varied the properties of pore-free polycrystalline magnesium aluminate spinel, which he considered as a possible high-performance structural ceramic on account of its chemical and thermal stability and multiple $\{111\}<110\rangle$ slip systems.

Three of the papers discussed the electrical properties of alumina. Drs. T. Matsumura and M. Laubitz (National Research Council, Canada) had calculated the ionic transport number from E.M.F. measurements on an $\mathrm{O}_{2}\left(p_{1}\right), \mathrm{Pt} / \mathrm{Al}_{2} \mathrm{O}_{3} / \mathrm{Pt}, \mathrm{O}_{2}\left(p_{2}\right)$ galvanic cell at temperatures $700^{\circ}-1,200^{\circ} \mathrm{C}$ and pressures $10^{-2}-1$ atm. Dr. Laubitz reported that their results were in agreement with the work of Sehmalried but disagreed with some other diffusivity measurements. This type of experiment can throw considerable light on the mechanism of grain boundary diffusion. Dr. V. Daniel (Electrical Research Association, Leatherhead) described her work with $\mathrm{Mr}$. M. Rogers on the degradation of ceramic insulators at high temperatures and the effects of various electrodo materials, with particular reference to the rectifying barriers formed at electrode-ceramic interfaces. Dr. A. J. Moulson had also considered, with Messrs. W. R. Phillips and P. Popper, the degradation of alumina ceramics, concentrating on measurements of the diffusion of the two commonost heater-current metals, nickel and chromium, into various grades of alumina and the effect of their oxide additions on the resistivity. Some discussion of mothods of measuring high-temperature resistivity to avoid surface and apparatus effects ensued. In an investigation of the effect of heat on pure single crystals of rutile, Mr. M. G. Harwood (Mullards, Ltd.) found that the d.c. stability at $150^{\circ} \mathrm{C}$ was raised whereas the a.c. losses were not correspondingly improved, indicating that different centres wero responsible, and that only some tri- and tetra-valent cations improved the d.c. stability.

Thermal conductivity and emissivity are of importance in high-temperature applications, and materials of low friction are required for high-temperature bearings. Dr. R. W. Powell presented some results which he and Mr. R. P. Tye had obtained at the National Physical Laboratory, using both the longitudinal heat-flow and thermal comparator methods for measuring the thermal conductivity of carbides and borides, and suggested that these should be considered as metallic alloys rather than covalent compounds. Mr. J. C. Titus-Glover described omissivity measurements at $1,500^{\circ}-2,500^{\circ} \mathrm{C}$ made with Dr. V. Croft at the University of Sheffield using a double parabolic are image furnace and low-resolution spectro- graph with a silicon cell radiometer. At the Cavendish Laboratory, Cambridge, Drs. C. A. Brookes and M. Imai had investigated the frictional properties of reactionsintered silicon nitride and silicon carbide. These compared well with metals and the coefficient of friction was independent of load. Surface finish was important for wear resistance.

In the session on fabrication techniques, Dr. S. Scholz described a neat hot-press that he and Dr. E. Roeder had used at the Philips Laboratory in Germany. It reached $3,200^{\circ} \mathrm{C}$ and $1,000 \mathrm{~kg} / \mathrm{cm}^{2}$ and accurate densification/time measurements on the small samples were recorded. Some of the limitations to hot-pressing for industrial applications have been overcome by Dr. G. S. Gruintjes and Mr. G.J. Oudemans (Philips Research Laboratories, Hindhoven), who described a new technique for continuous hot-pressing that had produced long rods of both metals and ceramics. Intense collimated plasma-electron beams of powers up to $5 \mathrm{~kW}$ had been obtained by Messrs. J. W. Isaacs, C. W. A. Maskell and J. D. L. Harrison at the Atomic Energy Research Establishment, Harwell, from robust, hollow cathodes without filaments, and Mr. Harrison discussed methods of controlling the energy and size of the beam and applications to the melting of ceramies.

Turning to future applications, Dr. E. Glenny's paper "Ceramics and the Gas Turbine", read by Mr. R. Smith (National Gas Turbine Establishment), attributed lack of early success in applying brittle materials in gas turbines to inadoquate effort, arising from insufficient incentive, and to the failure to re-design components to suit the new materials. The usefulness of materials at present available for heat exchangers, nozzle guide-vanes and coated turbine blades was discussed. Mr. N. R. Hemming (Bristol Siddeley) spoke of the need for refractory materials combining strength, toughness, lightness and oxidation resistance for use in air-breathing ramjet engines, which could advantageously be used in hypersonic aircraft capable of speeds of Mach No. 7, where wall temperatures would rise to $2,100^{\circ} \mathrm{C}$.

On behalf of the visitors, Dr. W. W. Shaver of Corning's, New York, thanked the British Ceramic Research Association for its hospitality. Following Dr. Astbury's formel closure of the symposium, the visitors were able to inspect some of the work being done at the Association's laboratories.

The Proceedings of the symposium will be edited by Mr. P. Popper and published by Academic Press, in the spring. $\quad$ S. N. RuDDlesden

\title{
PHENOLICS IN NORMAL AND DISEASED FRUITS AND VEGETABLES
}

T HE phenolic compounds of fruits and vegetables, their relationship to browning, their changes when plants are infected, and their role in resistance of plants to disease constituted the symposium topic for the fourth annual meeting of the Plant Phenolic Group of North America, at the Central Research Laboratories of the United Fruit Co., Norwood, Mass., during July 23-24.

The symposium opened with three papers on dopamine (3,4-dihydroxyphenylethylamine) based on research by the United Fruit Co. Dopamine, a major phenol in banana, is readily oxidized to form melanin. E. H. Buckley discussed the periods of dopamine accumulation, content, and distribution in banana peel and its biosynthesis via tyrosine and tyramine throughout the plant. J. K. Palmer outlined the enzymatic oxidation of dopamine to melanin by banana polyphenoloxidase (PPO) and the unique substrate specificity spectrum of banana PPO, with dopamine the most reactive by far. The inhibition of banana PPO in vitro was stressed. Reducing agents apparently worked by three different mechanisms, while the varied inhibition patterns of chelation agents indicated that other mechanisms were involved as well as chelation. Finally, M. E. Mace discussed the relationship between Fusarium wilt infection in banana roots and the phenolics present. Anatomical and histochemical investigations, as well as experiments in vitro and in vivo, were presented in support of the hypothesis that, in infected banana roots, oxidized dopamine mediates the conversion of tryptophan to indolyl-3-acetic acid. The IAA then induces localized tyloses that block the vascular elements and entrap spores, and thereby localize infection.

The first session was completed by a discussion of the anthocyanins of grapes by A. D. Webb (University of California, Davis). Only since the advent of paper chromatography has the complexity of anthocyanins in grapes been appreciated. Completely satisfactory methods for isolating the pigments in natural form are not yet available. Wines made from hybrids of Vitis vinifera with diseaseand cold-resistant native American species of grape can be detected by chromatography; this test is of legal impor- 
tance in France. $V$. vinifera fruits contain principally monoglucosides; the American varieties have, in addition, diglucosides (no other sugars have been detected). Acylated pigments are often present, with caffeic and $p$-coumaric acids as the combined acids.

A paper on enzymatic browning by J.W. Corse (Western Regional Research Laboratory, U.S. Department of Agriculture, Albany, Calif.) opened the second half of the symposium. The enzymes involved are copper-containing oxidases which are difficult to isolate and often appear to be mixtures. Molecular weights are of the order of 120,000 with perhaps four copper atoms; in some cases, the copper appears to be cuprous. The browning reaction occurs stepwise. After formation of a catechol group by introduction of a hydroxyl group, oxidation to $o$-quinones occurs. Finally, the latter polymerize non-enzymatically to dark substances, but the structure of the products is still not clear. Substrates in deciduous fruits include chlorogenic acid and related compounds. In attempts to control browning, physical methods and chemical agents have been abandoned in favour of a biochemical approach. $O$-Methyl transferase has been found to convert the catechol group to the browning-resistant guaiacyl group.

The role of phenolics in disease resistance in plants was discussed by J. Kuc' (Purdue University, Lafayette, Ind.). Increased production of chlorogenic and caffeic acids and a variety of aromatics occur both in response to disease and to wounding, the actual amount produced varying with the agent causing injury. These higherthan-normal concentrations, which are present especially on plant surface or at infection sites, inhibit microbial growth. The mechanisms by which micro-organisms bring about this increased production are varied and not yet completely understood. In general, they appear to be due to specific alterations in the metabolic pathways of both host and micro-organism. Resistance may then result from a shift in the very delicate metabolic balance.

The symposium coneluded with a paper by $\mathrm{T}$. Kosuge (University of California, Davis) outlining the present state of knowledge of the biosynthesis of the phenolic acids and coumarins which have been shown to accumulate in diseased tissue. Very few investigations of their biosyn. thesis in diseased plant tissues have been made, but considerable work has been done on healthy tissues. The acetate and shikimic acid pathways, which occur in higher plants, appear to be involved in the production of such compounds. The Proceedings of the symposium will be published in due course.

The officers for the Plant Phenolics Group of North America elected for the present year are: President, Dr. Margaret K. Seikel; Vice-president, Dr. Bernard J. Finkle; Secretary-Treasurer, Dr. V. C. Runeckles (Imperial Tobacco Co. of Canada, Ltd., Montreal, Canada).

Margaret K. Seikel

\section{PROBLEMS OF NOISE}

$A^{\mathrm{s}}$ long ago as 1948 the British Standards Institution published a code of practice entitled Sound Insula tion (Houses, Flats and Schools) (CP 3. Ch. 3; 1948). It had, of course, been a problem long before this, but since the Second World War the incidence of noise, in the home, in industry and out of doors, on the human being, has grown to be a matter not only of psychological but latterly of medical concern. That code tackled the problem of noise of both indoor and outdoor origin. It was largely concerned with means of reducing noise by appropriate siting, positioning and screening of windows in buildings. It included data of noise reduction values in 'phons' for different kinds of windows, open or shut. A revised B.S. Code (Ch. $3 ; 1960$ ), entitled Sound Insulation and Noise Reduction, followed. In the same year came the official Noise in Factories (Factory Building Studies, No. 6, H.M. Stationery Office, 1960); L. L. Beranek's Noise Reduction (McGraw-Hill, 1960), and a paper by D. E. Broadbent on "Effects of Noise Reduction in a Work Situation" (Occupational Psychology, April 1960). The last-mentioned author, who is director of the Medical Research Council Applied Psychology Research Unit, is also responsible for a more recent booklet, Noise in Industry, No. 6 in the series Ergonomics for Industry, prepared jointly by the Departmont of Scientific and Industrial Research Information Division and Warren Spring Laboratory*.

Undue noise is a matter which, in these modern days, affects us all in a great variety of ways, wherever we may be and whatever we are doing. On relaxed occasions it may be encouraged by certain members of the younger generation, abhorred by others more mature. But in day-to-day industrial occupations, it is quite another matter. There are three main reasons, as the author shows: ". . people do not like it, it damages their hearing and it has a bad effect on their working efficiency". These three effects are not necessarily interrelated. As he says: ". . . a noise which is very annoying may not be loud onough to damage hearing, or make people work less

* Department of Seientiflc and Industrial Research. Ergonomics for Industry, No. 6. Noise in Industry. By D. E. Broadbent. Pp. 16. (London: Laboratory, Stevenage, Herts, 1964.) well. On the other hand, there is the rather alarming possibility that noises which do not annoy people at all may quite often damage their hearing or impair their efficiency. It is important therefore to distinguish the various effects from one another and not to assume that all is well just because the workers in a noisy factory seem to be contented". Thus the theme of this booklet is to alert us to the effects, direct or more dangerously insidious, which noise may have on people at work and, it may be added, by inference in social environments where sometimes noise is cultivated for its own sake.

In modern measurements of sound, two technical terms are at present used. 'Cycles per second' (c/s) is the unit used to measure frequency. The 'decibel' (dB) measures the intensity. "The loudest sounds we may meet have an intensity of more than a million million times the intensity of the faintest sound we can hear. A scale of decibels takes this into account." The scale is logarithmic. Proportional changes in intensity are covered by the same number of units. Thus a ten-fold increase, 1-10, 10-100, $100-1,000$, etc., is represented by a change of $10 \mathrm{~dB}$. Impressive examples are given: $135 \mathrm{~dB}$ hydraulic press at $3 \mathrm{ft}$; $105 \mathrm{~dB}$ train whistle at $50 \mathrm{ft}$; $95 \mathrm{~dB}$ automatic lathe at close range; $75 \mathrm{~dB}$ office machines between desks; $65 \mathrm{~dB}$ speech at 3 or $4 \mathrm{ft}$.; $20 \mathrm{~dB}$ whisper at $4 \mathrm{ft}$.; and $0 \mathrm{~dB}$ threshold of hearing at 1,000 c/s. "It should also be noted that the smallest change apprceiated by the ear is about $1 \mathrm{~dB}$ where the change is in a faint sound or in a loud sound. $\mathrm{dB}$ figures are usually quoted with roference to an arbitrary zero-actually 0.0002 dynes $/ \mathrm{cm}^{2}$-which is approximately the faintest sound we can hear at $1,000 \mathrm{c} / \mathrm{s} . "$

This publication, although relatively brief, is convineing in its argument, supporting data, and message. The serious effects of noise on the ear, and on work efficiency, under manifold conditions, are incontrovertible. Some far-reaching conclusions from results of investigations into the hazards of noise are, cautiously, drawn by the author; among these may be cited: "The lovel of $90 \mathrm{~dB}$ is not too far from the level which has to be regarded as a threat to hearing; . . . if precautions are taken to prevent, deafness, they will also tend to prevent effects on working 